\title{
Expression of vesicle-associated membrane-protein-associated protein B cleavage products in peripheral blood leukocytes and cerebrospinal fluid of patients with sporadic amyotrophic lateral sclerosis
}

\author{
I. Deidda ${ }^{a}$, G. Galizzi ${ }^{a}$, R. Passantino ${ }^{a}$, C. Cascio $^{a}$, D. Russo ${ }^{a}$, T. Colletti ${ }^{b}$, V. La Bella ${ }^{b}$ and \\ P. Guarneria \\ ${ }^{\mathrm{a}}$ Neuroscience Unit, CNR Institute of Biomedicine and Molecular Immunology, Palermo; and ${ }^{\mathrm{b}}$ ALS Clinical Research Center, Department \\ of Experimental Biomedicine and Clinical Neurosciences, University of Palermo, Palermo, Italy
}

\section{Keywords:}

amyotrophic lateral sclerosis, cerebrospinal fluid, nematode major sperm protein, peripheral blood leukocytes, proteolysis, vesicleassociated membraneprotein-associated protein A, vesicleassociated membraneprotein-associated protein B

Received 28 June 2013

Accepted 18 November 2013
Background and purpose: Vesicle-associated membrane-protein-associated protein B (VAPB) is an endoplasmic reticulum (ER) resident protein participating in ER function, vesicle trafficking, calcium homeostasis and lipid transport. Its N-terminal domain, named MSP, is cleaved and secreted, serving as an extracellular ligand. VAPB mutations are linked to autosomal-dominant motor neuron diseases, including amyotrophic lateral sclerosis (ALS) type 8. An altered VAPB function is also suspected in sporadic ALS (SALS).

Methods: The expression pattern of VAPB cleavage and secreted products in the peripheral blood leukocytes (PBL) and cerebrospinal fluid (CSF) of SALS patients and neurological controls was assessed. PBL from healthy controls were also analyzed. Assays were carried out through western blotting, using an anti-VAPB (N-terminal) antibody.

Results: Two VAPB fragments containing the MSP domain (17 kDa and $14 \mathrm{kDa}$ molecular sizes) were identified in PBL of SALS and controls, with no significant differences amongst groups. In CSF, only the $14 \mathrm{kDa}$ VAPB MSP fragment was expressed and a corresponding VAPA fragment was not detected. The CSF VAPB fragment was absent in $58.7 \%$ of SALS patients, of whom $79.2 \%$ were bulbar onset $(P=0.001$, bulbar versus spinal).

Conclusions: The absence of the CSF VAPB MSP fragment from most bulbaronset SALS patients suggests a specific alteration of brain-derived VAPB cleavage and secretion in this group of patients, and hints at a role of VAPB in the pathophysiology of this motor neuron disease.

\section{Introduction}

Amyotrophic lateral sclerosis (ALS) is a neurodegenerative disease characterized by loss of the upper and lower motor neurons leading to a progressive muscle weakness and atrophy [1,2]. Death occurs within a few years after diagnosis, generally caused by respiratory failure [3]. Disease mechanisms are still undefined and only a few disease-modifying factors have been identified that might account for the heterogeneity of ALS clinical phenotypes [4-6].

Correspondence: P. Guarneri, Neuroscience Unit, CNR Institute of Biomedicine and Molecular Immunology, Via Ugo la Malfa 153, 90146 Palermo, Italy (tel.: + 39091-6809541/6809512; fax: + 390916809548; e-mail: pguarneri@ibim.cnr.it).
Whilst the majority of cases are sporadic ALS (SALS), about $10 \%$ are familial and linked to mutations in different genes [7,8]. Amongst these, a mutation in the gene encoding vesicle-associated membrane-protein-associated protein B (VAPB) has been described to cause either a slow progressive ALS, called ALS8, a late-onset spinal muscular atrophy, or a severe ALS with rapid progression $[9,10]$. The VAPB mutation, which results in a proline to serine substitution at position 56 (p.Pro56Ser), may behave as a dominant-negative protein ultimately leading to motor neuron death $[9,11]$.

The recent identification of VAPB mutations (T46I and V234I), with a patient remarkably harbouring both VAPBV234I mutation and C9orf72 
repeat expansion, strengthens the association of VAPB with clinically variable phenotypes $[9,10$, $12,13]$, and hints at an important implication of this protein in motor neuron pathology. Evidence also suggests that VAPB might have a role in SALS $[14,15]$.

VAPB belongs to the family of vesicle-associated membrane-protein-associated proteins, including VAPA and VAPC, which are endoplasmic reticulum (ER) resident proteins playing roles in vesicle trafficking, bouton formation at the neuromuscular junction, microtubule organization, calcium homeostasis, lipid transport and unfolded protein response [16,17]. Studies entail p.Pro56Ser mutation in an abnormal reorganization of ER structure causing altered unfolded protein responses and formation of insoluble aggregates [14,18-20].

There is evidence that VAPB undergoes proteolysis in rodent neuronal cells and human leukocytes $[11,21,22]$. The N-terminal domain, named MSP because of the homology with the major sperm protein from nematodes [16], can be secreted and found in human serum [11]. The secreted MSP fragment may act as an extracellular signal at selective postsynaptic receptors with a role in motor neuron survival and muscle function [11,23]. Of interest, p.Pro56Ser protein does not undergo proteolysis [11,22].

In this study, the expression of VAPB processing products in peripheral blood leukocytes (PBL) and cerebrospinal fluid (CSF) of patients with SALS was analysed. Two VAPB fragments containing the MSP domain were found in leukocytes and one in CSF, whereas the same expression pattern was not detected for the homologous VAPA. The PBL expression of the two VAPB fragments was similar in SALS patients and controls, which included healthy and neurological controls. Conversely, the expression of CSF VAPB MSP fragment was absent in most bulbar-onset SALS patients, suggesting an abnormal brain-derived VAPB processing and secretion.

\section{Materials and methods}

\section{Subjects}

Forty-six non-demented SALS patients (21 men, 25 women; $\mathrm{M} / \mathrm{F}=0.84$ ) were diagnosed according to the revised El Escorial/WFN criteria [24]. All patients were on riluzole therapy. None was with percutaneous endoscopic gastrostomy or under non-invasive ventilation at the time of CSF or blood drawing. Biological samples were taken at the time of the diagnostic work-up for each ALS patient enrolled. All patients belonged to stage $2 \mathrm{~A}(n=18,39.1 \%)$ or stage $2 \mathrm{~B}$
( $n=28,60.9 \%$ ), according to the staging system proposed by Roche et al. [25].

Twenty-two patients presented as spinal onset $(47.8 \%)$, whereas the remaining 24 were bulbar onset $(52.2 \%)$. Patients were submitted to a $30-\mathrm{ml}$ blood drawing for PBL purification and a lumbar puncture. Disease progression was rated at 3-month intervals with the clinimetric Appel ALS rating scale (AARS) [26]. At least three evaluations with AARS were considered sufficient to establish the rate of disease progression (i.e. slow, intermediate and rapid course).

Controls were age and sex matched to cases and consisted of 11 healthy subjects and 33 patients with neurological disorders not involving primarily motor neurons: Tapia's syndrome $(n=1)$; depressive disorder $(n=2)$; cervical spondylotic myelopathy $(n=4)$; non-inflammatory polyneuropathy $(n=7)$; conversion disorder $(n=4)$; Alzheimer dementia $(n=5)$; multiple sclerosis $(n=3)$; spinocerebellar ataxia $(n=2)$; primary progressive aphasia $(n=3)$; normal pressure hydrocephalus $(n=2)$.

The demographic and clinical characteristics of the ALS patients and control groups are summarized in Table 1.

This study was approved by the Ethics Committee of the Department of Experimental Biomedicine and Clinical Neurosciences, University of Palermo. Informed consent to the blood drawing and lumbar puncture was obtained from all subjects (i.e. ALS and neurological controls).

\section{PBL and CSF samples}

Peripheral venous blood and CSF samples were collected between 8:00 a.m. and 10:00 a.m. from fasted patients and controls, and labelled to ensure anonymity. CSF was immediately aliquoted and stored at $-80^{\circ} \mathrm{C}$ until analysis. Routine CSF analysis was within normal range in each patient or control. PBL were isolated using a dextran sedimentation method as

Table 1 Demographic and clinical characteristics of the amyotrophic lateral sclerosis (ALS) patients and controls

\begin{tabular}{lllll}
\hline & ALS & $\begin{array}{l}\text { Neurological } \\
\text { controls } \\
(n=46)\end{array}$ & $\begin{array}{l}\text { Healthy } \\
\text { controls } \\
(n=11)\end{array}$ & $P^{*}$ \\
\hline Age (years) & $62.1 \pm 11.05$ & $56.6 \pm 15.30$ & $54.3 \pm 12.00$ & 0.077 \\
M/F & 0.84 & 0.83 & 0.83 & \\
Clinical form $(\%)$ & & & \\
Bulbar & $24(52.2)$ & & & \\
Spinal & $22(47.8)$ & & & \\
\hline
\end{tabular}

Quantitative data are expressed as mean $\pm \mathrm{SD}$. *One-way ANOvA test. 
described by Skoog and Beck [27] and kept frozen at $-80^{\circ} \mathrm{C}$. Purified leukocytes were homogenized in icecold lysis buffer $[10 \mathrm{mM}$ phosphate $(\mathrm{pH} 7.4), 150 \mathrm{mM}$ $\mathrm{NaCl}, 5 \mathrm{mM} \mathrm{KCl}, 2 \mathrm{mM}$ EDTA, $2 \mathrm{mM}$ EGTA, 0.5\% Triton X-100 and protease inhibitors $(2 \mu \mathrm{g} / \mathrm{ml}$ aprotinin, $10 \mu \mathrm{g} / \mathrm{ml}$ leupeptin, $5 \mu \mathrm{g} / \mathrm{ml}$ pepstatin)], incubated in an ice bath for $30 \mathrm{~min}$ and centrifuged at $10000 \mathrm{~g}$ for $10 \mathrm{~min}$ at $4^{\circ} \mathrm{C}$. The resulting supernatants were stored at $-80^{\circ} \mathrm{C}$ until western blot analysis.

\section{Western blot analysis}

Protein extracts of PBL or CSF (65 or $100 \mu \mathrm{g}$ of proteins; Bio-Rad Bradford Protein Assay) were separated by $12 \% \mathrm{SDS} / \mathrm{PAGE}$ and transferred onto PVDF membranes. Membranes blocked with TBS buffer plus $0.1 \%$ Tween-20 and 5\% non-fat milk for $1 \mathrm{~h}$ were incubated with a polyclonal rabbit anti-human $(\mathrm{N}$ terminal) VAPB antibody (1:400, Proteintech Group Inc., Chicago, IL, USA) overnight at $4{ }^{\circ} \mathrm{C}$. Immunocomplexes were detected with horseradish-peroxidaseconjugated anti-rabbit antibody using Super-Signal West-Pico-Pierce. Membranes were reprobed with an anti- $\beta$-actin antibody (Clone AC-15; Sigma Aldrich, St. Louis, MO, USA) or an anti-human albumin antibody (Santa Cruz, Dallas, TX, USA) to confirm equal protein loading. In some experiments, a VAPA mouse anti-human monoclonal antibody (1-132 amino acids, aa) from R\&D Systems (Minneapolis, MN, USA; Clone \# 604101; 1:400) was used. Densitometry was performed using Chemi-Doc, Quantity-One analysis (Bio-Rad Laboratories, Segrate, Milam, Italy).

\section{Statistics}

The SIGMASTAT 3.5 software package (Systat Software Inc., Point Richmond, CA, USA) was used. Data are expressed as mean $\pm \mathrm{SD}$ and were analysed with ANOVA followed by a post hoc Neuman-Keuls analysis. The Mann-Whitney $U$ test was used to evaluate differences in the median PBL MSP-VAPB $/ \beta$-actin ratio or CSF MSP-VAPB $/ \beta$-albumin ratio between SALS and neurological controls (NC), and the Kruskal-Wallis test followed by Dunn's multiple comparison test. Differences between groups were also evaluated using the Fisher test. Statistical significance was set at $P<0.05$.

\section{Results}

\section{Characterization of VAPB processing products in PBL and CSF}

The topology of the human VAPB protein (243 aa residues) traces an $\mathrm{N}$-terminal domain (7-124 aa) that is homologous to the nematode major sperm protein and thus referred to as the MSP domain, a central coiled-coil domain (159-196 aa) and a short transmembrane anchor at the C-terminal region (220243 aa) (UniProt/Swiss-Prot-095292 and Fig. 1). To identify products containing the N-terminal MSP domain that were probably generated by VAPB proteolytic cleavage, a commercially available anti-human VAPB antibody raised against an epitope corresponding to the N-terminal region of $31-180$ aa residues (Proteintech Group) was used.

The expression pattern of VAPB and its MSP-containing fragments was initially investigated by western blot in PBL of healthy controls (HC) and non-ALS neurological subjects used herein as controls (NC). A small $30 \mathrm{kDa}$ band, which corresponded to the fulllength protein, and two major bands of approximately $17 \mathrm{kDa}$ and $14 \mathrm{kDa}$ were identified in both control groups (Fig. 2a). To optimize sensitivity of our detection and monitor differences in the $17 \mathrm{kDa}$ and $14 \mathrm{kDa}$ bands amongst samples, a lesser amount of protein extract $(65 \mu \mathrm{g})$ was used. As shown in Fig. 2 b, both bands were still strongly expressed in PBL but only the $14 \mathrm{kDa}$ band was detected in CSF. This was the exclusive band in CSF and no other bands were detected even at a higher protein concentration (i.e. $100 \mu \mathrm{g}$; data not shown), with the only exception being a $24 \mathrm{kDa}$ band noted in a very few cases. Specificity of bands in PBL and CSF was proved by VAPB antibody preabsorption with the immunogen peptide (Fig. 2c).

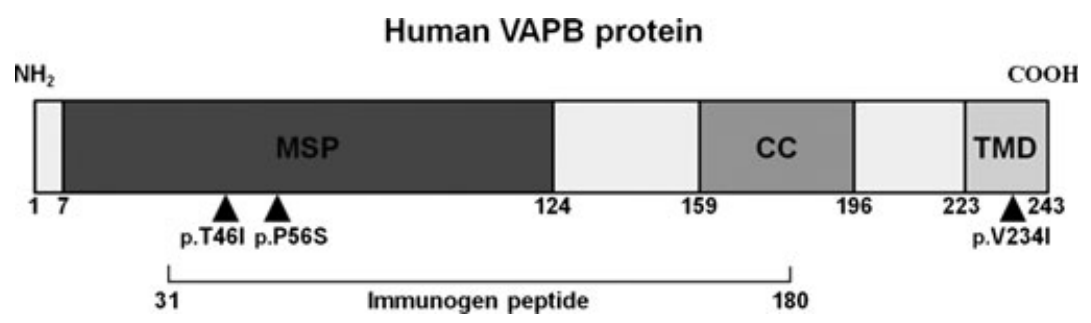

Figure 1 Schematic representation of structural domains of human VAPB protein. Positions of VAPB mutations (p.P56S, p.T46I and p.V234I) and immunogen peptide (31-180 aa) of the wild-type VAPB used to generate the anti-human VAPB antibody (Proteintech Group Inc.) are shown. 

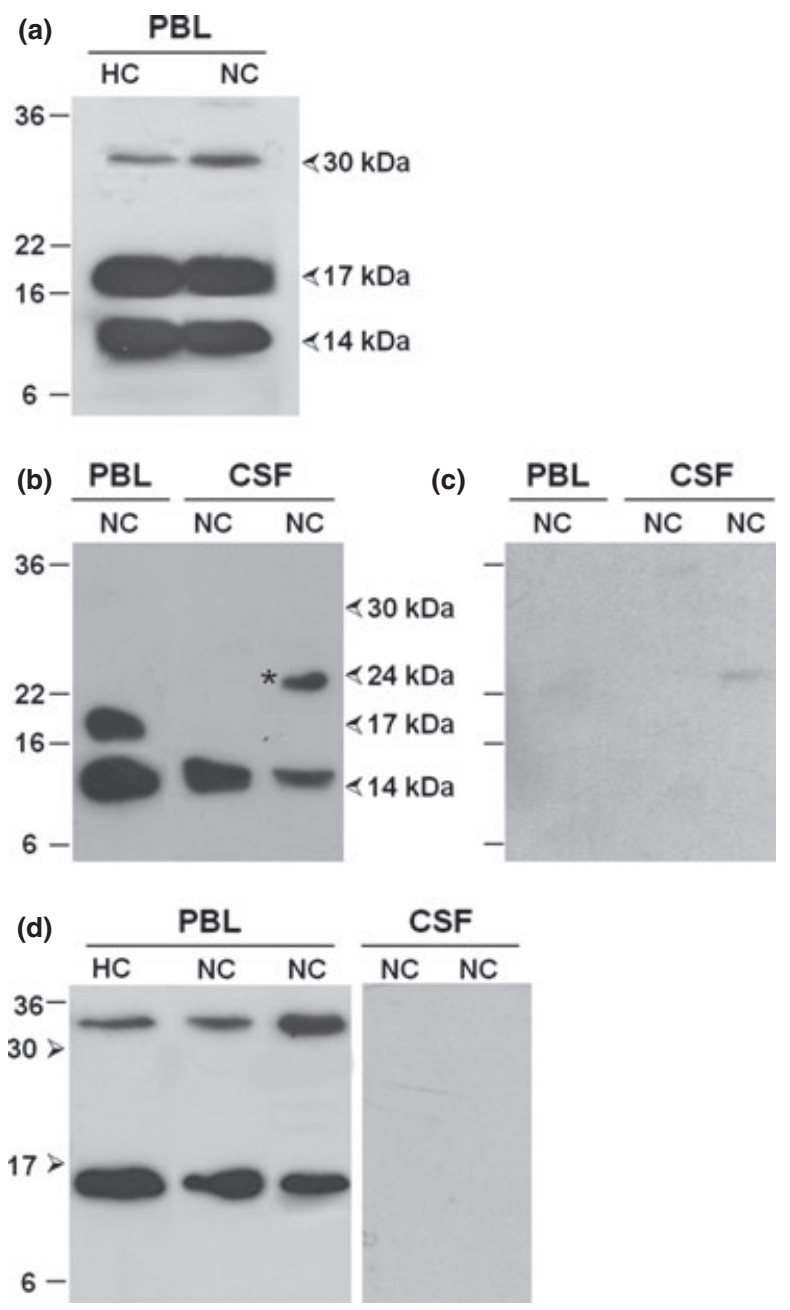

Figure 2 Expression of VAPB and VAPA proteins in PBL and CSF from healthy (HC) and neurological (NC) controls. (a), (b), (d) Representative immunoblots showing the expression pattern of VAPB (a), (b) and VAPA (d) identified in PBL and CSF. (c) Peptide competition experiments to verify specificity of the antiVAPB antibody. Western blots were carried out with (a) $100 \mu \mathrm{g}$ or (b)-(d) $65 \mu \mathrm{g}$ proteins of extracts. Differences in the molecular sizes of VAPB and VAPA bands are reported in leucocytes. VAPB and VAPA exhibit two close bands that approximate the molecular size of $17 \mathrm{kDa}$. In CSF, only the $14 \mathrm{kDa}$ band of VAPB was identified in most samples examined, and no VAPA product was detected; in rare instances, a $24 \mathrm{kDa}$ band of VAPB (asterisk) was additionally detected.

As VAPA is closely related to VAPB, sharing considerable sequence homology [28], the lack of crossreactivity was verified by analysing COS- 1 cell lysates expressing Myc-tagged VAPA with anti-VAPB antibody (Fig. S1). Furthermore, VAPA processing and secretion in the leukocytes and CSF of control groups was established using a monoclonal anti-human VAPA antibody (Fig. 2d). It was found that control leucocytes expressed full-length VAPA of about
$33 \mathrm{kDa}$ and only one other band that approximated the molecular size of $17 \mathrm{kDa}$ but differed from that of VAPB as shown by fluorescence-based western blot analysis (Fig. S2), whilst no band recognized by VAPA antibody was detected in CSF from NC patients $(n=10)$ or from ALS patients $(n=10)$ (data not shown).

Altogether, these results are consistent with the detection of two specific VAPB processing products $(17 \mathrm{kDa}$ and $14 \mathrm{kDa})$ in leukocytes and only one in CSF. The relatively low intensity of the full-length VAPB detected in PBL extracts of $\mathrm{HC}$ and $\mathrm{NC}$, even at an elevated protein concentration $(100 \mu \mathrm{g})$, suggests a high proteolytic processing in these cells. Indeed, in central nervous system (CNS) tissues of the adult mouse, having $89.7 \%$ homology with VAPB in humans, there was a higher expression of the fulllength VAPB and faint lower bands compared with the expression pattern of leukocytes (Fig. S3). On the other hand, the two identified bands show the expected sizes of a cleaved MSP-containing fragment of $17 \mathrm{kDa}$ previously detected in leukocytes [11] and of the exact MSP domain with a calculated size of $14 \mathrm{kDa}[29]$.

The expression of VAPB MSP-containing fragments in PBL $(n=26)$ and CSF $(n=46)$ of SALS patients and controls $(n=22$ for both HC and NC PBL; $n=33$ for NC CSF specimens) was then analysed. As shown in Fig. 3, scatter plot analyses did not reveal significant changes in the expression of either the $17 \mathrm{kDa}$ (Fig. 3a) or $14 \mathrm{kDa}$ (Fig. 3b) fragments in the PBL of SALS patients compared with controls. When the CSF $14 \mathrm{kDa}$ MSP was analysed (Fig. 4a and b), it was found that 29 of the $33 \mathrm{CSF}$ controls (NCCSF, $87.9 \%$ ) expressed the fragment, whereas it was only detected in $41.3 \%$ of SALS patients $(P=0.001$, Fischer exact test; Fig. 4b). By dividing SALS patients according to the site of onset, the $14 \mathrm{kDa}$ band was absent in $19 / 24(79.2 \%)$ patients with bulbar onset (ALS-B) and in $8 / 22(36.3 \%)$ patients with spinal onset $(P=0.006$, ALS-B vs. ALS-S, Fischer exact test; Fig. $4 \mathrm{~b})$. These results reveal that a great number of SALS patients $(58.7 \%)$ had brain-derived VAPB processing affected, and the majority of them were with bulbar onset.

These results were tentatively matched with the demographic and clinical variables. With the exception of the site of disease onset, no correlation with sex, age at onset, disease progression (evaluated by AARS) and diagnostic delay (data not shown) was found. It was also verified that the inclusion of patients with Alzheimer dementia, spinocerebellar ataxia and primary progressive aphasia in the NC group did not significantly influence our results. 

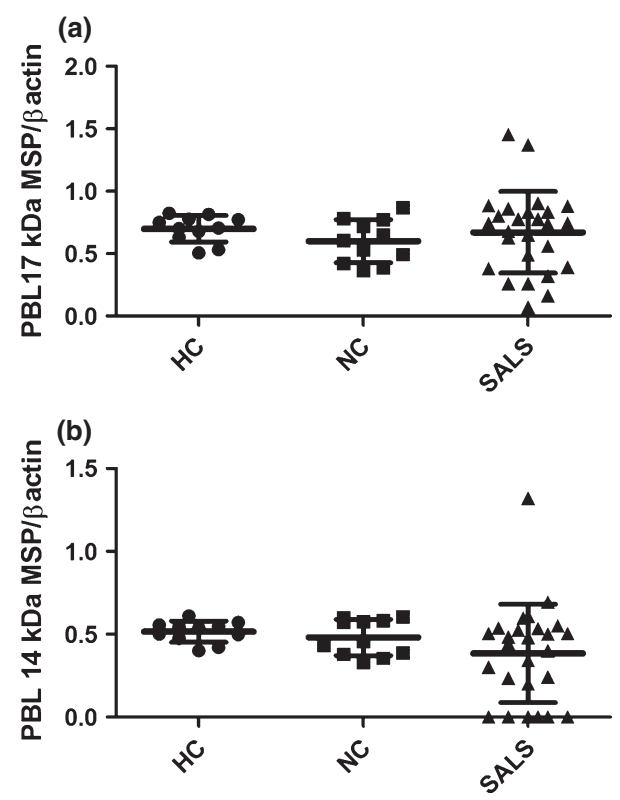

Figure 3 Scatter plots of the expression levels of VAPB MSP fragments in PBL of SALS patients and controls. Levels of the $17 \mathrm{kDa}$ (a) or $14 \mathrm{kDa}$ (b) fragments are expressed as the ratio between their intensities and those of $\beta$-actin immunoreactive bands. No significant differences for the two fragments were found amongst $\mathrm{HC}, \mathrm{NC}$ and SALS.

\section{Discussion}

It has been demonstrated that cleavage products of VAPB containing the MSP domain are expressed in PBL of SALS patients and controls with no differences between them, but the CSF MSP fragment is largely absent in patients with bulbar onset, thus suggesting a potential role of the VAPB MSP domain in the pathophysiology of this devastating neurodegenerative disorder.

Vesicle-associated membrane-protein-associated protein B cleavage has been previously described in human leukocytes and rodent brain tissues [11,22], and secretion of the N-terminal MSP domain in human serum has been reported as well [11]. Using an antiserum directed against $31-180$ aa residues of human VAPB, the presence of two bands of approximate sizes $17 \mathrm{kDa}$ and $14 \mathrm{kDa}$ in PBL and one band of $14 \mathrm{kDa}$ in CSF from a large number of subjects (including controls and SALS patients) is shown. The full-length VAPB in PBL was faintly expressed and it is suspected that VAPB processing may differ amongst cell types, being for instance higher in these peripheral cells than in neural tissues. VAP proteins and their truncated forms are expressed at different levels in rodent CNS tissues and organs, also increasing with age in the brain $[21,22]$. VAPB processing is an open question and requires more investigation.
Based on a $14 \mathrm{kDa}$ expected molecular mass for the MSP domain [29], it is presumed that the two molecular weight forms identified in leukocytes are both MSP-containing fragments resulting from a different cleavage process, and the CSF $14 \mathrm{kDa}$ peptide is instead the unique secreted MSP product of brainderived VAPB proteolytic processing. Specific VAPB cleavage and secretion was confirmed by the lack of CSF products of the VAPB homologous VAPA. Note that a band of $24 \mathrm{kDa}$ appeared in a few CSF samples, either from NC or SALS patients. This suggests an individual proteolytic processing or alternative splicing across individuals. The alternative mRNA transcripts of VAPB identified so far include VAPC with a lower molecular mass of $11 \mathrm{kDa}[16,29]$ and five new splice variants whose mRNAs are expressed in the human nervous system but their translation products have yet to be characterized [30]. These and our observations are important issues for further investigation. However, given the limited and unpredictable appearance of this band, it was not considered in our present analysis.

This study is the first showing secretion of an MSPcontaining peptide of VAPB, but not of VAPA, in human CSF. So far, human VAPB MSP secretion has been suggested by the homology with the Caenorhabditis elegans and Drosophila MSPs [11,23], and only Tsuda et al. [11] reported VAPB MSP secretion in human serum. The mechanism of this secretion still remains obscure. However, it is shown here that the secreted MSP correlates with SALS disease. Our results in fact reveal that the expression of the $17 \mathrm{kDa}$ and $14 \mathrm{kDa}$ MSP-containing fragments was unchanged in PBL extracts of SALS patients and controls, but the $14 \mathrm{kDa}$ fragment was absent in the CSF of more than half of SALS patients compared with NC. The expression levels of CSF did not correlate with those of leukocytes and no correlation was found even in those patients with the lowest expression of fragments in leukocytes, thus excluding an impairment of VAPB at the transcriptional level.

A reduction in VAPB expression has been seen in the post-mortem spinal cord of SALS patients, mostly marked in the rapidly progressing group who died within 3 years from diagnosis [15]. Interestingly, it was found that $79.2 \%$ of SALS patients with absent CSF $14 \mathrm{kDa}$ MSP fragment had bulbar onset. These observations point to a key role of VAPB in the pathogenesis of motor neuron degeneration.

Several lines of evidence support the hypothesis that pathophysiological mechanisms may differ between patients with bulbar and spinal onset. For instance, levels of phosphorylated neurofilament heavy-subunit and growth hormone in CSF and serum are higher in 
(a)

\begin{tabular}{|c|c|c|c|c|c|c|c|c|c|c|c|c|c|c|c|}
\hline $14 \mathrm{kDa}$ & \#1 & \#2 & \#3 & \#4 & \#5 & \#6 & \#7 & $\# 8$ & $\# 9$ & $\# 10$ & \#11 & $\# 12$ & $\# 13$ & \#14 & \#15 \\
\hline MSP & & & $\cdots$ & & & & & & & & & & & & \\
\hline Albumin & & & & & & & & & & & & & & & \\
\hline
\end{tabular}

\begin{tabular}{|c|c|c|c|c|c|c|c|c|c|c|c|c|c|c|c|}
\hline \multirow{3}{*}{$\begin{array}{r}14 \mathrm{kDa} \\
\mathrm{MSP}\end{array}$} & \multicolumn{15}{|c|}{ ALS-B CSF } \\
\hline & \#1 & $\# 2$ & $\# 3$ & $\# 4$ & \#5 & \#6 & \#7 & \#8 & $\# 9$ & $\# 10$ & $\# 11$ & $\# 12$ & $\# 13$ & $\# 14$ & $\# 15$ \\
\hline & & & & & & $\square$ & & & & & & & & & \\
\hline bumin & & & & & & & & & & & & & & & \\
\hline
\end{tabular}

\begin{tabular}{|c|c|c|c|c|c|c|c|c|c|c|c|c|c|c|c|}
\hline \multirow{3}{*}{$\begin{array}{r}14 \mathrm{kDa} \\
\mathrm{MSP}\end{array}$} & \multicolumn{15}{|c|}{ ALS-S CSF } \\
\hline & $\# 16$ & $\# 17$ & $\# 18$ & $\# 19$ & $\# 20$ & $\# 21$ & \#22 & \#23 & $\# 24$ & $\# 25$ & $\# 26$ & $\# 27$ & $\# 28$ & $\# 29$ & $\# 30$ \\
\hline & & $\infty$ & & & & & $\bullet$ & & & & & & & & \\
\hline Ibumin & & & & & & & & & & & & & & & \\
\hline
\end{tabular}
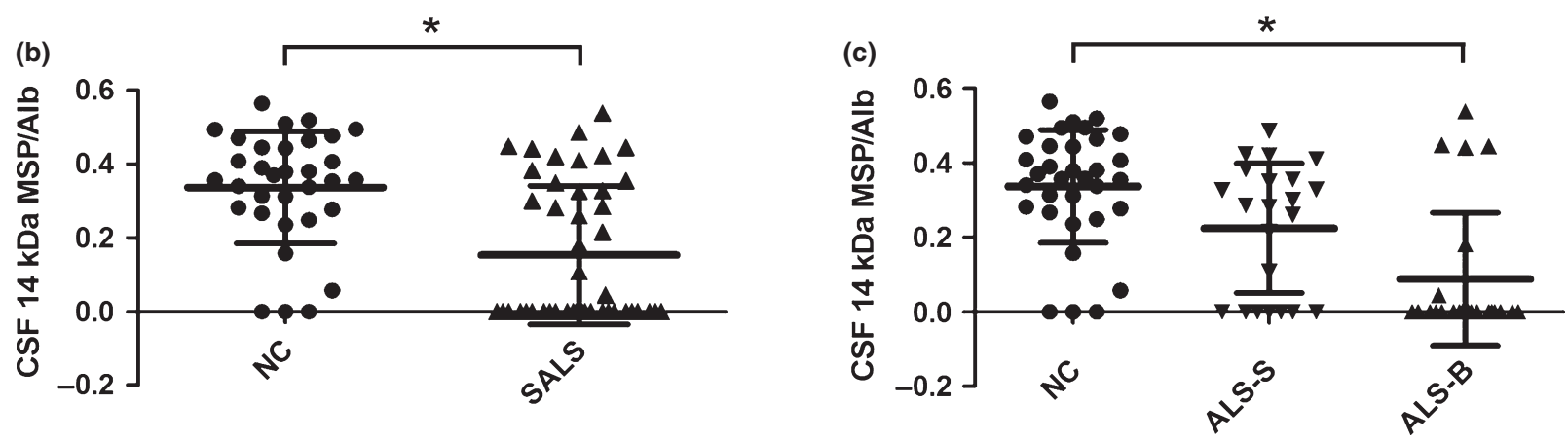

Figure 4 Analyses of the VAPB MSP fragment in CSF from neurological controls (NC) and SALS patients with bulbar (ALS-B) and spinal onset (ALS-S). (a) Representative immunoblots of the CSF $14 \mathrm{kDa}$ fragment from 15 subjects analysed of each group; albumin immunoblotting was used to control protein loading. (b), (c) Scatter plots of the expression levels of the CSF VAPB MSP fragment detected in the samples examined (NC, $n=33$; SALS, $n=46$; ALS-S, $n=22$; ALS-B, $n=24$ ). Western blot analyses of VAPB MSP were performed in triplicate using the same amount of proteins $(65 \mu \mathrm{g})$ for each CSF sample and by reprobing membranes with albumin antibody. Levels of the $14 \mathrm{kDa}$ fragment result from the ratio of the fragment over albumin density in each sample on western blotting. (a) *Mann-Withney $U$ test $(P<0.0001$, NC vs. SALS); (b) *Kruskal-Wallis test with Dunn's multiple comparison test $(P<0.0001, \mathrm{NC}$ vs. ALS-B)

bulbar-onset ALS patients than in the spinal-onset patients, and CSF erythropoietin levels are lower in bulbar-onset ALS [31-34]. Age at onset, epidemiological and brain metabolism data also strengthen differences between bulbar- and spinal-onset forms of ALS $[35,36]$. Our results indeed support the likelihood of different pathophysiological states in the two conditions.

The MSP domain of VAPB has been suggested to act as an extracellular ligand for ephrin receptors, NMDA receptors and LAR-Robo co-receptors, so having effects on motor neuron survival and muscle energy metabolism $[11,23]$. A p.Pro56Ser mutation in this domain leads to failure of secretion, and this is supposed to be another possible cause of motor neuron degeneration in certain cases of familial ALS, such as ALS8 type $[11,22,23]$. The mutated and uncleaved VAPB has been suggested to form cytoplasmic aggregates in the ER, thus altering its homeostasis [37]. Interestingly, Qiu et al. [38] have recently suggested that aggregates of the mutated VAPB do not cause motor neuron degeneration by a gain of toxicity, but a loss of function may be the underlying mechanism.

VAPB or C9orf72, FUS, TARDP and SOD1 mutations were not found in our ALS cases (L. Conforti, personal communication). VAPB MSP fragment, however, was undetected in the CSF of SALS patients, and in particular in the bulbar-onset group. It is therefore possible that a tissue-specific post-translational failure to produce a cleaved MSP fragment might contribute to the pathogenesis of this devastating motor neuron disease. 
In conclusion, our study demonstrates a reduced VAPB MSP fragment expression in the CSF of SALS, and expands our knowledge of the pathogenic role of VAPB in this motor neuron disorder. Most bulbaronset patients had undetectable VAPB-derived fragment, and this supports the hypothesis that the two main ALS phenotypes (i.e. bulbar- and spinal-onset ALS) may at least in part be driven by diverse pathophysiological mechanisms.

\section{Acknowledgements}

This work was supported by research grants from the Italian Ministry of Health (no. G71J07000010001) to VLB and PG, and PNR-CNR Aging Program 20122014 to PG. The authors gratefully acknowledge all ALS patients as well as the control patients who made this study possible.

\section{Disclosure of conflicts of interest}

The authors declare no financial or other conflicts of interest.

\section{Supporting Information}

Additional Supporting Information may be found in the online version of this article:

Figure S1. Western blot of endogenous and recombinant VAPA proteins showing anti-VAPB antibody specificity.

Figure S2. Different expression pattern of VAPB and VAPA in leucocytes analysed through fluorescencebased western blot.

Figure S3. Fluorescence-based western blot of human PBL and mouse CNS tissues with anti-VAPB antibody.

\section{References}

1. Bruijn LI, Miller TM, Cleveland DW. Unraveling the mechanisms involved in motor neuron degeneration in ALS. Annu Rev Neurosci 2004; 27: 723-749.

2. Kiernan MC, Vucic S, Cheah BC, et al. Amyotrophic lateral sclerosis. Lancet 2011; 377: 942-955.

3. Spataro R, Lo Re M, Piccoli T, Piccoli F, La Bella V. Causes and place of death in Italian patients with amyotrophic lateral sclerosis. Acta Neurol Scand 2010; 122: 217-223.

4. Ravits JM, La Spada AR. ALS motor phenotype heterogeneity, focality, and spread: deconstructing motor neuron degeneration. Neurology 2009; 73: 805811.

5. Dupuis L, Spreux-Varoquaux O, Bensimon G, et al. Platelet serotonin level predicts survival in amyotrophic lateral sclerosis. PLoS One 2010; 5: e13346.
6. Ludolph AC, Brettschneider J, Weishaupt JH. Amyotrophic lateral sclerosis. Curr Opin Neurol 2012; 25: 530-535.

7. Andersen PM, Al-Chalabi A. Clinical genetics of amyotrophic lateral sclerosis: what do we really know? Nat Rev Neurol 2011; 7: 603-615.

8. Cooper-Knock J, Hewitt C, Highley JR, et al. Clinicopathological features in amyotrophic lateral sclerosis with expansions in C9ORF72. Brain 2012; 135: 751-764.

9. Nishimura AL, Mitne-Neto M, Silva HC, et al. A mutation in the vesicle-trafficking protein VAPB causes lateonset spinal muscular atrophy and amyotrophic lateral sclerosis. Am J Hum Genet 2004; 75: 822-831.

10. Marques VD, Barreira AA, Davis MB, et al. Expanding the phenotypes of the Pro56Ser VAPB mutation: proximal SMA with dysautonomia. Muscle Nerve 2006; 34: 731-739.

11. Tsuda H, Han SM, Yang Y, et al. The amyotrophic lateral sclerosis 8 protein VAPB is cleaved, secreted, and acts as a ligand for Eph receptors. Cell 2008; 133: 963977.

12. Chen HJ, Anagnostou G, Chai A, et al. Characterization of the properties of a novel mutation in VAPB in familial amyotrophic lateral sclerosis. $J$ Biol Chem 2010; 285: 40266-40281.

13. van Blitterswijk M, van Esa A, Max Koppers M, et al. VAPB and C9orf72 mutations in 1 familial amyotrophic lateral sclerosis patient. Neurobiol Aging 2012; 33: 2950.e1-4.

14. Teuling E, Ahmed S, Haasdijk E, et al. Motor neuron disease-associated mutant vesicle-associated membrane protein-associated protein (VAP) B recruits wild-type VAPs into endoplasmic reticulum-derived tubular aggregates. $J$ Neurosci 2007; 27: 9801-9815.

15. Anagnostou G, Akbar MT, Pau P, et al. Vesicle associated membrane protein B (VAPB) is decreased in ALS spinal cord. Neurobiol Aging 2010; 31: 969-985.

16. Lev S, Halevy DB, Peretti D, Dahan N. The VAP protein family: from cellular functions to motor neuron disease. Trends in Cell Biol 2008; 18: 6282-6290.

17. De Vos KJ, Mórotz GM, Stoica R, et al. VAPB interacts with the mitochondrial protein PTPIP51 to regulate calcium homeostasis. Hum Mol Genet 2012; 21: 12991311.

18. Suzuki H, Kanekura K, Levine TP, et al. ALS-linked P56S-VAPB, an aggregated loss-of-function mutant of VAPB, predisposes motor neurons to ER stress-related death by inducing aggregation of co-expressed wild-type VAPB. J Neurochem 2009; 108: 973-985.

19. Kim S, Leal SS, Halevy DB, Gomes CM, Lev S. Structural requirements for VAP-B oligomerization and their implication in amyotrophic lateral sclerosis-associated VAP-B(P56S) neurotoxicity. J Bio. Chem 2010; 285: 13839-13849.

20. Papiani G, Ruggiano A, Fossati M, et al. Restructured endoplasmic reticulum generated by mutant amyotrophic lateral sclerosis-linked VAPB is cleared by the proteasome. J Cell Sci 2012; 125: 3601-3611.

21. Gkogkas C, Middleton S, Kremer AM, et al. VAPB interacts with and modulates the activity of ATF6. Hum Mol Genet 2008; 17: 1517-1526.

22. Gkogkas C, Wardrope C, Hannah M, Skehel P. The ALS8-associated mutant VAPB (P56S) is resistant to proteolysis in neurons. $J$ Neurochem 2011; 117: 286-294. 
23. Han SM, Tsuda H, Yang Y, et al. Secreted VAPB/ ALS8 major sperm protein domains modulate mitochondrial localization and morphology via growth cone guidance receptors. Dev Cell 2012; 22: 348-362.

24. Brooks BR, Miller RG, Swash M, Munsat TL. El Escorial revisited: revised criteria for the diagnosis of amyotrophic lateral sclerosis. Amyotroph Lateral Scler Other Motor Neuron Disord 2000; 1: 293-299.

25. Roche JC, Rojas-Garcia R, Scott KM, et al. A proposed staging system for amyotrophic lateral sclerosis. Brain 2012; 135: 847-852.

26. Appel V, Stewart SS, Smith G, Appel SH. A rating scale for amyotrophic lateral sclerosis: description and preliminary experience. Ann Neurol 1987; 22: 328-333.

27. Skoog WA, Beck WS. Studies on the fibrinogen, dextran and phytohemagglutinin methods of isolating leukocytes. Blood 1956; 11: 436-454.

28. Nishimura Y, Hayashi M, Inada H, Tanaka T. Molecular cloning and characterization of mammalian homologues of vesicle-associated membrane protein-associated (VAMP-associated) proteins. Biochem Biophys Res Commun 1999; 254: 21-26.

29. Mitne-Neto M, Ramos CR, Pimenta DC, et al. A mutation in human VAP-B-MSP domain, present in ALS patients, affects the interaction with other cellular proteins. Protein Expr Purif 2007; 55: 139-146.

30. Nachreiner T, Esser M, Tenten V, Troost D, Weis J, Krüttgen A. Novel splice variants of the amyotrophic lateral sclerosis-associated gene VAPB expressed in human tissues. Biochem Biophys Res Commun 2010; 394: 703-708.
31. Corbo M, Lunetta C, Magni P, et al. Free insulin-like growth factor (IGF)-1 and IGF-binding proteins-2 and -3 in serum and cerebrospinal fluid of amyotrophic lateral sclerosis patients. Eur J Neurol 2010; 17: 398-404.

32. Boylan KB, Glass JD, Crook JE, et al. Phosphorylated neurofilament heavy subunit (pNF-H) in peripheral blood and CSF as a potential prognostic biomarker in amyotrophic lateral sclerosis. J Neurol Neurosurg Psychiatry 2012; 84: 467-472.

33. Saccà $\mathrm{F}$, Quantarelli $\mathrm{M}$, Rinaldi $\mathrm{C}$, et al. A randomized controlled trial of growth hormone in amyotrophic lateral sclerosis: clinical, neuroimaging and hormonal results. J Neurol 2012; 259: 132-138.

34. Janik P, Kwiecinski H, Sokolowska B, Niebroj-Dobosz I. Erythropoietin concentration in serum and cerebrospinal fluid of patients with amyotrophic lateral sclerosis. J Neural Transm 2010; 117: 343-347.

35. Cellura E, Spataro R, Taiello AC, La Bella V. Factors affecting the diagnostic delay in amyotrophic lateral sclerosis. Clin Neurol Neurosurg 2012; 114: 550-554.

36. Cistaro A, Valentini CM, Chiò A, et al. Brain hypermetabolism in amyotrophic lateral sclerosis: a FDG PET study in ALS of spinal and bulbar onset. Eur $J$ Nucl Med Mol Imaging 2012; 39: 251-259.

37. Ackerman SL, Cox GA. From ER to Eph receptors: new roles for VAP fragments. Cell 2008; 13: 949-951.

38. Qiu L, Qiao T, Beers M, et al. Widespread aggregation of mutant VAPB associated with ALS does not cause motor neuron degeneration or modulate mutant SOD1 aggregation and toxicity in mice. Mol Neurodegener 2013; 8: 1 . 